\title{
Malaria in pregnancy pilot projects nationally adopted in Kenya and Malawi
}

Population Council

Follow this and additional works at: https://knowledgecommons.popcouncil.org/departments_sbsr-rh

Part of the Demography, Population, and Ecology Commons, Family, Life Course, and Society Commons, Gender and Sexuality Commons, International Public Health Commons, Maternal and Child Health Commons, Medicine and Health Commons, and the Women's Health Commons How does access to this work benefit you? Let us know!

\section{Recommended Citation}

"Malaria in pregnancy pilot projects nationally adopted in Kenya and Malawi," FRONTIERS OR Summary. Washington, DC: Population Council, 2008. 
Kenya, Malawi Safe Motherhood

\section{OR Summary 77}

\title{
Malaria in Pregnancy Pilot Projects Na- tionally Adopted in Kenya and Malawi
}

\begin{abstract}
Measures to prevent malaria among antenatal clients in Kenya and Malawi were shown to be sustainable several years after the pilot interventions ended. In Malawi, the approach has been expanded nationwide. Kenya and Malawi have developed national policies to prevent malaria in pregnancy.
\end{abstract}

\section{Background}

In most malaria-endemic areas of Africa, women in their first and second pregnancies have the highest risk of acquiring malaria and, consequently, of malaria-associated anemia and low birth weight. Two USAID-funded interventions aimed at strengthening the prevention and management of malaria in pregnancy (MIP) were pilot-tested at the district level in Kenya (1998-2002) and Malawi (1998-2004). These were the Bungoma District Malaria Initiative (BDMI) in Kenya, implemented by the Ministry of Health $(\mathrm{MOH})$ and the African Medical and Research Foundation, and the Blantyre Integrated Malaria Initiative (BIMI) in Malawi, carried out by the government of Malawi, USAID, and the Centers for Disease Control and Prevention.

The goal of the projects was to reduce malaria illness and death among children and mothers primarily by: 1) giving Intermittent Presumptive Treatment (IPT) of sulfadoxide-pyrimethamine (SP) to pregnant women visiting antenatal clinics (ANCs), and 2) promoting the use of insecticide-treated bed nets (ITNs) by pregnant women through subsidizing the prices, aggressive promotion and wide distribution.

In 2005 and 2006, FRONTIERS conducted case studies to assess the sustainability of these initiatives, documented best practices for promoting their scale-up, and drew lessons for replication in other East and Southern African countries where malaria is endemic. Data were gathered from desk reviews, assessment of facilities in Bungoma and Blantyre (45 and 29, respectively), surveys of women who had delivered in the past six months (330 and 401), and interviews with key informants (10 and 29).

\section{Findings}

Sustainability in pilot districts

- MIP prevention continued after introduction of the intervention. Inventories show that most of the facilities surveyed (37 of 45 in Kenya and 26 of 29 in Malawi) were still offering MIP service two or more years after the pilot projects ended.

- Of the 330 Kenyan women who had delivered in the past six months, 36 percent received the first dose of SP, 33 percent received the second dose, but 31 percent did not receive any SP-similar proportions to those found in 2002 at the end of the BDMI project. In Malawi, 80 percent of women received SP at least once and 66 percent received it twice. About 15 percent of women received the three recommended doses, and about 20 percent did not receive any SP.

- Use of bednets was limited at the end of the Kenya intervention, but the proportion of women sleeping under ITNs increased significantly by the time of the evaluation study (from 3\% to 58\%). In Malawi, 81 percent of facilities provided ITNs, and nearly 70 percent of women surveyed reported sleeping under a treated net. 


\section{Scale-up: Kenya}

- BDMI contributed to Kenya's adoption of IPT as a national policy with a target of 60 percent use of ITNs by 2006. SP is now available overthe-counter, and ITNs are available at subsidized prices to facilitate access by low-income clients. MIP services have been integrated into health plans and staff training routines, including training for traditional birth attendants.

- However, implementation of MIP policy has lagged in Kenya. A 2005 survey by Population Services International showed only 25 percent coverage with ITNs; and as of 2006, only 11 percent of ANC providers had received training on IPT for pregnant clients.

- Kenyan policy states that ANC is a no-fee service that includes MIP. However, national survey data showed that 37 percent of facilities in Western Province, where the BDMI was implemented, did charge a fee for ANC in 2005. This may limit access to MIP services.

\section{Scale-up: Malawi}

- IPT activities have been adopted as national programs and cover all 28 districts. National surveys show that a large proportion of women receiving ANC (90\% of pregnant women) received first and second doses of SP $(93 \%$ and $60 \%$, respectively) in 2004. Use of ITNs by pregnant women doubled between 2004 and 2006 (from $32 \%$ to $68 \%$ ).

\section{Factors enhancing sustainability}

- In Kenya, integration of the MIP within the existing health system strengthened sustainability. Strong community awareness of the IPT program helped to mobilize community anti-malaria actions, such as re-treatment of bednets, to prevent malaria. Kenya's participation in regional antimalaria initiatives, such as Rollback Malaria and the Abuja Declaration, helped to position IPT as a national priority.

- In Malawi, the MOH prioritized malaria as a national problem and committed to a systematic, long-term search for solutions, including use of evidence-based interventions, development of simplified MIP guidelines for providers and the public, and a target of eliminating malaria as a public health problem within 20 to 30 years.

- This commitment to a specific goal and to an evidence-based approach elicited high levels of support from development partners. Strong links within the $\mathrm{MOH}$ and with district- and community-level organizations also enhance the potential for sustainability.

\section{Policy Implications}

- Considering malaria within a strategic framework outlining national priorities, evidence-based solutions, and specific long-term goals establishes a strong basis for sustainability. Interventions must be integrated within existing service delivery systems.

Sources: Onyango-Ouma, W., Harriet Birungi, and Annie Mwangi. 2007. "The potential for sustainability of malaria in pregnancy initiatives in East and Southern Africa: The Bungoma District Malaria Initative, Kenya," FRONTIERS Final Report. Washington, DC: Population Council. See Also: Okuonzi, Sam Agatre, Doreen Ali, and Harriet Birungi. 2007. The potential for sustainability of malaria in pregnancy initiatives in East and Southern Africa: Lessons from Blantyre Integrated Malaria Initiative, Malawi," FRONTIERS Final Report. Washington, DC: Population Council. See Also: Onayango-Uma, W. et al. 2008. "The potential for sustainability of malaria in pregnancy initiatives in East and Southern Africa: Kenya and Malawi," FRONTIERS Final Report. Washington, DC: Population Council. [In press] Available on our website at www.popcouncil.org/frontiers or by e-mail: publications@popcouncil.org.

This publication is made possible by the generous support of the American people through the President's Emergency Plan for AIDS Relief (PEPFAR) and the United States Agency for International Development (USAID) under the terms of Cooperative Agreement No. HRN-A-00-98-00012-00. The contents are the responsibility of the FRONTIERS Program and do not necessarily reflect the views of USAID or the United States Government. 